\title{
Menopausal Symptoms and Higher Risk Opioid Prescribing in a National Sample of Women Veterans with Chronic Pain
}

\author{
Carolyn J. Gibson, PhD, MPH ${ }^{1,2}$, Yongmei Li, $P h D^{7}$, Alison J. Huang, MD, MAS ${ }^{2}$, \\ Tessa Rife, PharmD, BCGP, CACP ${ }^{1,2}$, and Karen H. Seal, MD, MPH ${ }^{1,2}$
}

'San Francisco VA Health Care System, San Francisco, USA; ${ }^{2}$ University of California, San Francisco, San Francisco, USA.

BACKGROUND: The greatest increases in long-term opioid use and opioid-related overdose mortality in recent years have been among women in midlife. Common menopausal symptoms broadly affect health and health care utilization in midlife, but their contribution to chronic pain management during this period is unknown.

OBJECTIVE: To examine relationships between menopausal symptoms and long-term opioid prescription patterns among midlife women with chronic pain.

DESIGN: Cross-sectional analysis of national Veterans Health Administration medical and pharmacy records (2014-2015).

PARTICIPANTS: Women Veterans aged 45-64 with $\geq 1$ outpatient visit and chronic pain diagnoses spanning $\geq$ 90 days.

MAIN MEASURES: Long-term opioids (prescribed oral opioids for $\geq 90$ days), high-dose long-term opioids (>50 mg average morphine equivalent daily dose), and long-term opioids co-prescribed with central nervous system depressants (benzodiazepine and non-benzodiazepine sedative-hypnotics, gabapentin/pregabalin, muscle relaxants). Multivariable logistic regression models were used to examine associations between outcomes and menopausal symptoms (menopausal symptom-related diagnoses (i.e., "symptomatic menopausal states") on $\geq 2$ encounters and/or menopausal hormone therapy, adjusting for race, age, body mass index, and mental health and substance use disorder diagnoses.

KEY RESULTS: In this national sample of 104,984 midlife women Veterans with chronic pain (mean age 54.5, SD 5.4 years), $17 \%$ had evidence of menopausal symptoms, $51 \%$ were prescribed long-term opioids, $13 \%$ were prescribed high-dose long-term opioids, and 35\% were coprescribed long-term opioids and central nervous system depressants. In multivariable analyses, women with

Prior Presentations Preliminary findings from this research were presented at the North American Menopause Society 2017 Annual Meeting (Philadelphia, PA, October 11-14, 2017) and the Society of General Internal Medicine 2018 Annual Meeting (Denver, CO, April 11-14, 2018). 2019 HSR\&D/QUERI National Conference (Washington, D.C., October 29-31, 2019)

Electronic supplementary material The online version of this article (https://doi.org/10.1007/s11606-019-05242-w) contains supplementary material, which is available to authorized users.

Received December 26, 2018

Revised May 15, 2019

Accepted July 9, 2019

Published online August 14, 2019 menopausal symptoms had increased odds of long-term opioids (OR 1.21, 95\% CI 1.18-1.26), high-dose long-term opioids (OR 1.08, 95\% CI 1.02-1.13), and long-term opioids co-prescribed with central nervous system depressants (sedative-hypnotics OR 1.25, 95\% CI 1.22-1.30; gabapentin/pregabalin OR 1.23, 95\% CI 1.20-1.27; muscle relaxants OR 1.24, 95\% CI 1.20-1.28).

CONCLUSIONS: Among midlife women Veterans with chronic pain, evidence of menopausal symptoms was associated with potentially risky long-term opioid prescription patterns, independent of known risk factors.

KEY WORDS: women's health; menopause; opioids; chronic pain; Veterans.

J Gen Intern Med 34(10):2159-66 DOI: $10.1007 / \mathrm{s} 11606-019-05242-\mathrm{w}$

(c) Society of General Internal Medicine (This is a U.S. government work and not under copyright protection in the U.S.; foreign copyright protection may apply) 2019

\section{INTRODUCTION}

Women are disproportionately affected by the ongoing opioid epidemic. ${ }^{1}$ This is a particular concern in the Veterans Health Administration (VA), ${ }^{2}$ where women Veterans are a growing population with complex care needs, including higher rates of chronic pain, opioid receipt, and mental health comorbidities than their male peers. ${ }^{3}$ Across health care settings, women are more likely than men to have chronic pain, ${ }^{3,4}$ to be prescribed opioids, ${ }^{1,5,6}$ and to have opioid prescription patterns linked to misuse and overdose risk. These include being prescribed opioids at higher doses, ${ }^{7}$ for a longer duration, ${ }^{8}$ and co-prescribed with central nervous system (CNS) depressants. ${ }^{1}$ These patterns are pronounced among women in their $40 \mathrm{~s}, 50 \mathrm{~s}$, and into their $60 \mathrm{~s}^{8}$

Over the past two decades, the greatest increases in longterm opioid use ${ }^{1}$ and opioid-related overdose mortality ${ }^{8,9}$ have been among women in midlife. This may be related to changes in pain experience and pain management over the menopausal transition. Chronic health comorbidities ${ }^{10}$ and hormonal changes $^{11}$ related to menopause and aging increase risk for chronic pain and pain sensitivity. Common menopausal symptoms, including hot flashes, mood symptoms, and sleep difficulty, may share etiologic mechanisms with and/or exacerbate chronic pain, ${ }^{10,12}$ affecting pain management. Among women with chronic pain treated with opioids, pharmacological 
treatment of menopausal symptoms with CNS depressants, including sedative-hypnotics for anxiety and insomnia; ${ }^{13}$ gabapentin for mood symptoms, ${ }^{14}$ insomnia, ${ }^{13}$ and hot flashes and night sweats; ${ }^{15}$ and muscle relaxants for arthralgia, ${ }^{15}$ may lead to potentially high-risk polypharmacy. ${ }^{16}$ Within this vulnerable period, women with chronic pain and menopausal symptoms may be at elevated risk for potentially problematic opioid prescribing patterns.

In this study, we used national VA medical record data from midlife women Veterans with chronic pain, a leading diagnosis within the largest age group of women served by VA, ${ }^{17}$ to compare long-term opioid prescription patterns between those with and without menopausal symptoms. We hypothesized that independent of known risk factors, women with menopausal symptoms would have higher odds of being prescribed long-term opioids, high-dose long-term opioid, and coprescribed CNS depressants.

\section{METHODS}

\section{Data Source}

Data for this cross-sectional study were drawn from VA administrative data sources: (1) the Decision Support System's National Data Extract of pharmacy data, a comprehensive database of medications dispensed through VA pharmacies, and (2) the VA National Patient Care Database, containing International Classification of Diseases, Ninth Revision Clinical Modification (ICD-9-CM) diagnostic codes from electronic medical records generated during clinical visits. The primary analytic cohort includes women Veterans aged 45-64 with chronic non-cancer pain and at least one VA outpatient encounter between January 1, 2014, and December 31, 2015. This age range was selected to be comparable with midlife age categorization in previous studies of opioid prescribing, ${ }^{1}$ and to limit assessment to the age range that menopausal symptoms are most commonly reported. ${ }^{18}$ Chronic pain was defined by ICD-9 codes indicating the same pain diagnosis category (online appendix) on at least two encounters spanning $\geq 90$ days during the observed period, an approach used in prior VA administrative data studies. ${ }^{19}$ The study was approved by the institutional review boards of the University of California, San Francisco, and the Research and Development Committee of the San Francisco VA Health Care System.

\section{Variables}

Menopausal symptoms were assessed by data abstraction from pharmacy and medical records in 2014-2015. Menopausal symptoms were categorized by (1) menopause-related diagnoses including postmenopausal atrophic vaginitis, specified and unspecified menopausal disorders, and symptomatic menopausal states including hot flashes and sleep difficulty (online appendix) on at least two encounters, or (2) menopausal hormone therapy prescriptions filled at least once during the observed period, as treatment of menopausal symptoms is the primary indication for this prescription. Since some hormone preparations can be used for other indications (e.g., contraception, gender-affirming hormone therapy), expert clinician review (AH) was used to distinguish oral, transdermal, and vaginal hormone preparations primarily used for menopausal symptoms. While this approach does not capture unreported symptoms, it allows for detection of symptoms that are considered severe enough to warrant discussion, evaluation, documentation, and/or treatment by a health care provider.

Opioid prescriptions were derived from pharmacy records of dispensed medications during 2014-2015. Long-term opioids were defined as prescribed oral opioid medications for $\geq$ 90 days over the observed period, consistent with past definitions using VA data. ${ }^{20}$ Patch formulations and buprenorphine were not included, as these are non-formulary in the VA with use restricted to treatment of cancer/palliative care pain (fentanyl) and opioid use disorder (buprenorphine, oral or patch). High-dose long-term opioids were defined as longterm opioids with a mean morphine equivalent daily dose (MEDD) $\geq 50 \mathrm{mg}$, calculated from the average dose of all long-term opioid use over the observed period. This threshold was chosen based on dosage risk profiles and VA guideline recommendations. ${ }^{21}$ MEDD was also categorized as $<20 \mathrm{mg}$, 20 to $<50 \mathrm{mg}, 50$ to $<100 \mathrm{mg}$, and $\geq 100 \mathrm{mg}$ for descriptive analyses. Long-term opioids co-prescribed with CNS depressants were defined as long-term opioids with a prescription for a $\geq 5$-day supply of (1) sedative-hypnotics (benzodiazepines and non-benzodiazepine sedative-hypnotics including alprazolam, chlordiazepoxide, clonazepam, clorazepate, diazepam, flurazepam, lorazepam, oxazepam, temazepam, triazolam, zolpidem, eszopiclone, zaleplon, and ramelteon), (2) gabapentin or pregabalin, or (3) muscle relaxants (baclofen, carisoprodol, cyclobenzaprine, methocarbamol, tizanidine, and metaxalone) overlapping for 1+ day in the observed period. These were chosen as medications commonly prescribed to women in midlife for indications related to menopausal symptoms, ${ }^{13-15}$ with known ${ }^{22}$ and emerging ${ }^{23-27}$ literatures supporting misuse and mortality risk in combination with opioids.

Demographic and health-related covariates were obtained from outpatient medical records during 2014-2015. All covariates were selected a priori due to known relationships with chronic pain management. 3, 20, 28, 29 Age was defined as age on January 1, 2014, based on medical record-documented birth date. Race was categorized as white, black, other, or missing (if not available), based on self-reported race in the medical record. Race categories combined in the "other" category each comprised $\leq 1 \%$ of the overall sample. Body mass index (BMI) was identified from physical examination measurements from outpatient encounters, categorized as underweight/normal (<25), overweight (25-29.9), and obese $(30+)$, or missing if unavailable. Mental health diagnoses (posttraumatic stress disorder, depression, anxiety disorder) and substance use disorders (substance use disorder, alcohol 
use disorder) were defined by ICD-9 codes on more than one encounter in the observed period (online appendix).

\section{Statistical Analyses}

Descriptive statistics were used to summarize key variables and covariates, including frequencies and percentages for categorical data and means and standard deviations for continuous data. Chi-square analyses were used to examine unadjusted differences in (1) long-term opioid patterns and (2) long-term opioid dosages (restricted to any long-term opioids) between women with and without medical record evidence of menopausal symptoms.

Multivariable logistic regression models were used to examine associations between menopausal symptoms and longterm opioids (referent, no long-term opioids), high-dose longterm opioids (referent, 0-50 mg MEDD), and long-term opioids co-prescribed with CNS depressants (benzodiazepine and non-benzodiazepine sedative-hypnotics, gabapentin/ pregabalin, and muscle relaxants; referent, no long-term opioids or long-term opioids without co-prescription). Associations between menopausal symptoms and each outcome were assessed in separate models. All models were adjusted for age, race, BMI, any mental health diagnosis, and any substance use disorder diagnosis. All analyses were performed using SAS 9.4 (SAS Institute Inc., 2013; Cary, NC) and Stata 14 (StataCorp, 2015; College Station, TX).

\section{RESULTS}

\section{Characteristics of the Sample}

The final analytic sample was comprised of 104,984 midlife women Veterans with chronic pain (mean age $54.5 \pm$ 5.4 years). Overall, the sample was largely white (58\%), and overweight (27\%) or obese (47\%). PTSD was documented for $23 \%$ of women in the sample; $17 \%$ had depression, $20 \%$ had an anxiety disorder, and $11 \%$ had an alcohol or substance use disorder. Evidence of menopausal symptoms in the medical record was observed for $17 \%$ of women. Over half of all women in the sample were prescribed long-term opioids, and one in ten women in the sample was prescribed long-term opioids $\geq 50 \mathrm{mg}$ MEDD. Among all women in the sample, over a third received long-term opioids were co-prescribed with a CNS depressant (Table 1). Although not examined as an outcome, co-prescription with multiple CNS depressants was also common (i.e., 22\% co-prescribed opioids, sedative-hypnotics, and gabapentin/pregabalin; data not shown).

\section{Menopausal Symptoms and Long-term Opioids}

In unadjusted analyses, evidence of menopausal symptoms was more prevalent in women with all higher risk opioid prescribing patterns (data not shown). Among women prescribed long-term opioids, those with medical record evidence of menopausal symptoms were more likely to be prescribed $\geq$ 100 mg MEDD (Fig. 1).

In multivariable analyses adjusted for age, race, BMI, and mental health and substance use disorder diagnoses, women with evidence of menopausal symptoms had increased odds of long-term opioids (vs. no long-term opioids), high-dose longterm opioids (vs. 0-49 MEDD), and long-term opioids coprescribed with CNS depressants (vs. no opioids or long-term opioids with no co-prescribed CNS depressants). Women also had increased odds of long-term opioids and long-term opioids co-prescribed with CNS depressants if they were older, were black, were overweight or obese, or had mental health and substance use disorders. Age, mental health, and substance use disorders were also associated with increased odds of highdose long-term opioids (Table 2).

\section{DISCUSSION}

In this national sample of midlife women Veterans with chronic pain, we examined associations between long-term opioid prescription patterns and evidence of menopausal symptoms. One in two women was prescribed long-term opioids, one in ten was prescribed high-dose long-term opioids, and one in three were co-prescribed long-term opioids and CNS depressants at some point during the 2 -year observed period. Independent of established demographic and clinical risk factors, the odds of each of these potentially high-risk prescription patterns were up to $25 \%$ higher among women with menopausal symptoms.

These novel findings suggest that menopausal symptoms may be related to problematic opioid prescribing among women in midlife with chronic pain, a population with dramatically increasing rates of opioid use ${ }^{1}$ and opioid-related overdose mortality. ${ }^{8,} 9$ Although menopause affects pain experience in midlife, ${ }^{10,30,31}$ the role of menopausal symptoms in chronic pain management has not been previously examined. To our knowledge, this study is the first to identify associations between indicators of menopausal symptoms and long-term and high-dose long-term opioid prescription patterns, which may be explained by multiple pathways. Long-term opioid use may lower estrogen levels, potentially precipitating or exacerbating menopausal symptoms. ${ }^{32}$ Menopausal symptoms perceived as bothersome may reflect general somatic symptom sensitivity, ${ }^{33}$ influencing treatment-seeking and treatment decisions for both pain and menopausal symptoms. Common correlates of menopausal symptoms, including physical and mental health comorbidities ${ }^{33,34}$ and health risk behaviors such as limited physical activity, ${ }^{35,} 36$ also present known challenges to pain management ${ }^{29}, 37,38$ that may influence provider decisions to prescribe long-term and high-dose longterm opioids.

Of note, mental health conditions related to menopausal symptoms ${ }^{33}$ have been linked to higher rates of opioid receipt and long-term use. ${ }^{29,} 39$ Opioid use may attenuate emotional 
Table 1 Characteristics of 104,984 Midlife Women Veterans with Chronic Pain Diagnoses

\begin{tabular}{|c|c|c|c|c|c|c|}
\hline \multicolumn{4}{|l|}{ Long-term opioids } & \multicolumn{3}{|c|}{ Any long-term opioids + CNS depressants ${ }^{\ddagger}$} \\
\hline & $\begin{array}{l}\text { No long-term } \\
\text { opioids }(n= \\
51,921, \\
49.5 \%)\end{array}$ & $\begin{array}{l}\text { Any long-term } \\
\text { opioids* }(n= \\
53,063,50.5 \%)\end{array}$ & $\begin{array}{l}\text { Long-term } \\
\text { opioids } \geq \mathbf{5 0} \text { mg } \\
\text { MEDD }^{\dagger}(n= \\
\mathbf{1 3 , 8 5 8 , 1 3 . 2 \% )}\end{array}$ & $\begin{array}{l}\text { Long-term opioids } \\
\text { + sedative- } \\
\text { hypnotics }(n= \\
33,147,31.6 \%)\end{array}$ & $\begin{array}{l}\text { Long-term opioids }+ \\
\text { gabapentin// } \\
\text { pregabalin }(n= \\
\mathbf{3 3 , 3 4 9 , 3 1 . 8 \% )}\end{array}$ & $\begin{array}{l}\text { Long-term opioids } \\
+ \text { muscle } \\
\text { relaxants }(n= \\
42,265,40.3 \%)\end{array}$ \\
\hline Menopausal & $7944(15.3 \%)$ & $9693(18.3 \%)$ & $2753(19.9 \%)$ & $6670(20.1 \%)$ & $6471(19.4 \%)$ & $7985(18.9 \%)$ \\
\hline $\begin{array}{l}\text { symptoms } \\
\text { Age, in years } \\
\text { (mean, SD) }\end{array}$ & $54.3(5.4)$ & $54.7(5.3)$ & $55.1(5.2)$ & $54.7(5.3)$ & $54.7(5.3)$ & $54.6(5.3)$ \\
\hline $\begin{array}{l}\text { Race } \\
\text { White }\end{array}$ & $\begin{array}{l}30,295 \\
(58.4 \%)\end{array}$ & $30,307(57.1 \%)$ & $8910(64.3 \%)$ & $20,186(60.9 \%)$ & $19,400(58.2 \%)$ & $23,904(56.6 \%)$ \\
\hline Black & $\begin{array}{l}16,744 \\
(32.3 \%)\end{array}$ & $18,579(35.0 \%)$ & $3859(27.9 \%)$ & $10,417(31.4 \%)$ & $11,439(34.3 \%)$ & $15,094(35.7 \%)$ \\
\hline \multicolumn{5}{|c|}{ Body mass index $\left(\mathrm{kg} / \mathrm{m}^{2}\right)$} & $1150(3.5 \%)$ & $1468(3.5 \%)$ \\
\hline $\begin{array}{l}\text { Underweight/ } \\
\text { normal }(<25)\end{array}$ & $9699(18.7 \%)$ & $8778(16.5 \%)$ & $2739(19.8 \%)$ & $5789(17.5 \%)$ & $5502(16.5 \%)$ & $6881(16.3 \%)$ \\
\hline $\begin{array}{l}\text { Overweight (25- } \\
29.9)\end{array}$ & $\begin{array}{l}14,145 \\
(27.2 \%)\end{array}$ & $13,735(25.9 \%)$ & $3646(26.3 \%)$ & $8713(26.3 \%)$ & $8639(25.9 \%)$ & $10,993(26.0 \%)$ \\
\hline Obese $(30+)$ & $\begin{array}{l}22,969 \\
(44.2 \%)\end{array}$ & $26,250(49.5 \%)$ & $6551(47.3 \%)$ & $16,098(48.6 \%)$ & $16,699(50.1 \%)$ & $21,059(49.8 \%)$ \\
\hline \multicolumn{7}{|c|}{ Mental health diagnoses } \\
\hline Depression & $6719(12.9 \%)$ & $10,832(20.4 \%)$ & $3567(25.7 \%)$ & $8730(26.3 \%)$ & $8007(24.0 \%)$ & $9253(21.9 \%)$ \\
\hline Anxiety & $8921(17.2 \%)$ & $11,964(22.6 \%)$ & $3779(27.3 \%)$ & $9692(29.2 \%)$ & $8450(25.3 \%)$ & $10,039(23.8 \%)$ \\
\hline Posttraumatic & $9862(19.0 \%)$ & $14,502(27.3 \%)$ & $4751(34.3 \%)$ & $11,711(35.3 \%)$ & $10,410(31.2 \%)$ & $12,246(29.0 \%)$ \\
\hline $\begin{array}{l}\text { stress disorder } \\
\text { Alcohol use } \\
\text { disorder }\end{array}$ & $2285(4.4 \%)$ & $3486(6.6 \%)$ & $1094(7.9 \%)$ & $2547(7.7 \%)$ & $2527(7.6 \%)$ & $2865(6.8 \%)$ \\
\hline $\begin{array}{l}\text { Substance use } \\
\text { disorder }\end{array}$ & $1621(3.1 \%)$ & $3803(7.2 \%)$ & $1653(11.9 \%)$ & $2956(8.9 \%)$ & $2980(8.9 \%)$ & $3290(7.8 \%)$ \\
\hline
\end{tabular}

All opioid and CNS depressant prescriptions dispensed during observed period, 2014 and 2015

MEDD, morphine equivalent daily dose

Data not shown: race $(n=5183)$, body mass index $(n=9408)$ categorized as missing

*Prescribed oral opioid medications for $\geq 90$ days

${ }^{*}$ Average dose of all long-term opioids $\geq 50 \mathrm{mg}$ morphine equivalent daily dose (MEDD)

${ }^{*}$ Long-term opioids and overlapping prescription ( $\geq 1$ day) of CNS depressants (> 5-day supply)

distress by dampening neural activity in the limbic system and related structures that process both emotional and physical pain, ${ }^{40}$ which may explain increased use among women with

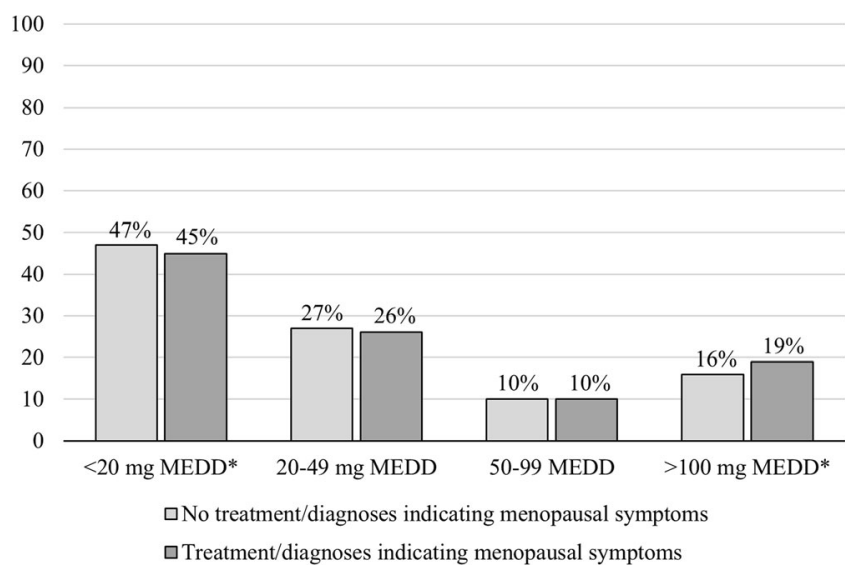

Figure 1 Mean morphine equivalent dose (MEDD) categories among women Veterans with chronic pain prescribed long-term opioids $(n=53,063)$. MEDD calculated as average dose of all long-term opioids over observed period. Among women with any long-term opioids during observed period, chi-square analyses were used to compare unadjusted prevalence rates of long-term opioids between women with and without evidence of menopausal symptoms. $p<.001$ for overall comparisons across dosage categories; $* p<.001$ for comparisons within dosage categories. mental health comorbidities. ${ }^{39}$ Although opioids have not been studied, recommended, or FDA-approved for these indications, these findings suggest that long-term and high-dose opioids may be inadvertently prescribed to manage inadequately treated menopausal symptoms among midlife women with chronic pain.

Among midlife women with chronic pain treated with opioids, concurrent treatment of menopausal symptoms may contribute to potentially high-risk polypharmacy. In this study, women with menopausal symptoms were more likely to be coprescribed long-term opioids with CNS depressants, including benzodiazepine and non-benzodiazepine sedative-hypnotics, gabapentin/pregabalin, and muscle relaxants. Although the intended indications for these prescriptions cannot be verified with these data, these co-prescribed medications are commonly used for menopause-related indications. ${ }^{15,41,42}$ Specifically, sedative-hypnotics are often prescribed for anxiety and/or sleep difficulties, common in the peri- and postmenopause, ${ }^{42}$ and muscle relaxants are used to treat menopausal arthralgia. ${ }^{41}$ Similarly, gabapentin/pregabalin is prescribed for neuropathic pain and fibromyalgia, ${ }^{43}$ common among women in midlife, and increasingly prescribed off-label for mood symptoms, sleep difficulty, ${ }^{14}$ and menopausal hot flashes and night sweats. ${ }^{15,44}$ Each of these medications have abuse potential, ${ }^{24}$, 
Table 2 Adjusted Odds of Opioid Prescription Patterns by Menopausal Symptoms

\begin{tabular}{|c|c|c|c|c|c|}
\hline & \multicolumn{2}{|c|}{ Long-term opioids } & \multicolumn{3}{|c|}{ Long-term opioids + CNS depressants $ף$} \\
\hline & $\begin{array}{l}\text { Any long-term } \\
\text { opioids }{ }^{\S} \text { OR } \\
(95 \% \text { CI })\end{array}$ & $\begin{array}{l}\text { Long-term opioids } \\
\geq \mathbf{5 0} \text { mg MEDD } \\
\text { OR (95\% CI) }\end{array}$ & $\begin{array}{l}\text { +Sedative-hypnotics } \\
\text { OR (95\% CI) }\end{array}$ & $\begin{array}{l}\text { +Gabapentin/ } \\
\text { pregabalin } \\
\text { OR }(95 \% \mathrm{CI})\end{array}$ & $\begin{array}{l}\text { +Muscle relaxants } \\
\text { OR }(95 \% \mathrm{CI})\end{array}$ \\
\hline Menopausal symptoms & $1.21(1.18-1.26)$ & $1.08(1.02-1.13)^{*}$ & $1.25(1.22-1.30)$ & $1.23(1.22-1.30)$ & $1.24(1.20-1.28)$ \\
\hline Age & $1.02(1.01-1.02)$ & $1.02(1.01-1.02)$ & $1.01(1.01-1.02)$ & $1.01(1.01-1.02)$ & $1.01(1.00-1.02)$ \\
\hline \multicolumn{6}{|l|}{ Race } \\
\hline White & Referent & Referent & Referent & Referent & Referent \\
\hline Black & $1.14(1.11-1.17)$ & $0.67(0.64-0.70)$ & $1.03(1.02-1.06)^{* *}$ & $1.11(1.08-1.13)$ & $1.16(1.13-1.19)$ \\
\hline Other & $0.94(0.88-1.01)$ & $0.97(0.87-1.08)$ & $0.90(0.85-0.96)^{* *}$ & $0.93(0.87-0.99)^{\dagger}$ & $0.95(0.89-1.01)^{\dagger \dagger}$ \\
\hline \multicolumn{6}{|l|}{ Body mass index } \\
\hline Underweight/normal $(<25)$ & Referent & Referent & Referent & Referent & Referent \\
\hline Overweight (25-29.9) & $1.09(1.05-1.13)$ & $0.86(0.81-0.91)$ & $1.07(1.03-1.11)$ & $1.09(1.06-1.13)$ & $1.10(1.06-1.14)$ \\
\hline Obese $(30+)$ & $1.30(1.25-1.34)$ & $0.82(0.78-0.87)$ & $1.24(1.20-1.28)$ & $1.29(1.25-1.34)$ & $1.29(1.25-1.34)$ \\
\hline Any mental health diagnosis & $1.64(1.60-1.69)$ & $1.61(1.55-1.68)$ & $2.10(2.05-2.15)$ & $1.78(1.73-1.82)$ & $1.71(1.67-1.75)$ \\
\hline Substance/alcohol use disorder & $1.59(1.52-1.67)$ & $1.60(1.51-1.70)$ & $1.60(1.53-1.67)$ & $1.68(1.60-1.75)$ & $1.56(1.49-1.63)$ \\
\hline
\end{tabular}

MEDD, morphine equivalent daily dose

All models adjusted for age, race, body mass index, any mental health diagnosis, and substance/alcohol use disorder

Any mental health diagnosis includes depressive disorders, anxiety disorders, and/or posttraumatic stress disorder

Data not shown: race, body mass index categorized as missing

${ }^{*} p=.004, * p=.01,{ }^{*} p=.02,{ }^{*} p=.08$; all other values shown significant at $p<.001$

${ }^{8}$ Referent: no long-term opioids

"Referent: < $50 \mathrm{mg}$ MEDD (including no opioids)

"Referent: no long-term opioids or long-term opioids without co-prescribed CNS depressants

41, 42 particularly when used concomitantly with opioids, ${ }^{45}$ and contribute to opioid-related mortality. ${ }^{26,46}$ These findings extend past research demonstrating higher rates of coprescribed opioids and sedative-hypnotics in women, ${ }^{1}$ identifying a gender-specific risk factor for co-prescription and highlighting other understudied but potentially high-risk combinations in this population.

These findings have important clinical implications. The long-term opioid prescription patterns associated with menopausal symptoms in this study can contribute to risk for opioid misuse, opioid-related overdose mortality, and other adverse health outcomes. Observed odds were independent from those of previously identified risk factors, including comorbid mental health and substance use disorder diagnoses. ${ }^{29,}{ }^{47}$ Risk of developing opioid use disorder ${ }^{48}$ and risk for opioid over$\operatorname{dose}^{49}$ are elevated with long-term use and higher doses, and dramatically increased when opioids are co-prescribed with CNS depressants. ${ }^{49}$ When co-prescribed with CNS depressants, opioids are often prescribed for a longer duration and at higher doses than when prescribed alone. ${ }^{49}$ Misuse, dependence, and disability related to sedative-hypnotics independent of opioid use have been well-documented, ${ }^{42}$ and benzodiazepines are implicated in $30 \%$ of opioid-related overdose deaths. ${ }^{49}$ A growing literature also describes the abuse potential of gabapentin ${ }^{23}$ and muscle relaxants, ${ }^{41}$ with misuse of each increased in the context of comorbid opioid use. ${ }^{23,41,46}$ While patient behaviors cannot be determined from this data, these findings suggest provider-driven treatment decisions that may contribute to risk for misuse, disability, and overdose, even when medications are taken as prescribed.

The clinical risks related to these long-term opioid prescription patterns may be particularly high for midlife and older women with chronic pain. Long-term opioid use with and without co-prescribed CNS depressants augments risk for primary health concerns in aging populations, including cognitive impairment, ${ }^{48,50}$ fracture risk, ${ }^{48,}{ }^{50}$ physical dependence, ${ }^{51}$ and poor health outcomes. ${ }^{52}$ Additionally, common aging-related chronic health conditions, such as obstructive sleep apnea, increase risk for overdose mortality. ${ }^{50}$ Even among women with a seemingly acceptable safety profile in midlife, the long-term nature of opioid prescribing for chronic pain may result in increasing risk for adverse health outcomes and opioid-related misuse and overdose with age.

Racial differences in prescribing may further augment these relationships among black women, who had greater odds of being prescribed long-term opioids both alone and coprescribed with CNS depressants than white women in this study. This finding contradicts past reports of higher opioid prescribing among whites relative to racial/ethnic minorities. $^{28,53,54}$ However, racial differences in prescribing by gender may not have been observed in the absence of gender-stratified or gender-specific samples, frequently drawn from largely male populations such as the VA. ${ }^{53,54}$ Further, some research suggests that racial differences in prescribing patterns may be reversed in older adults, ${ }^{28}$ which may be reflected in this sample.

These findings should be interpreted with caution. Longitudinal trends including the duration of hormone therapy, menopausal diagnoses, or opioid receipt, as well as temporal relationships between them, cannot be determined with these cross-sectional data. Given the large sample size, small differences that may not be clinically significant may be statistically significant. This study uses data from midlife women Veterans who use VA healthcare, a population at elevated risk for 
chronic pain and long-term opioid use with high rates of medical and mental health comorbidities. ${ }^{17}$ Results may not be generalizable to women Veterans who do not use VA healthcare, or to women in the general population. We cannot confirm the validity or chronicity of diagnoses in the medical record. Reliance on ICD-9-CM codes likely underrepresents diagnoses related to menopausal symptoms, which may be infrequently discussed and/or documented in VA settings. Although hormone therapy also served as a proxy for menopausal symptoms, only a fraction of symptomatic women use hormone therapy. ${ }^{15}$ Women with documented menopausal symptoms may differ in their willingness to discuss sensitive, often stigmatized, symptoms with their providers. These patient characteristics may also lead to increased reporting of symptoms related to chronic pain, and subsequent receipt of opioids to treat chronic pain.

Pharmacy data was limited to VA records, and we cannot account for non-VA prescriptions. We can only ascertain prescription patterns based on dispensed medications, not actual use or misuse of those medications. Finally, the VA implemented opioid safety initiatives in 2013 , and national changes in opioid prescribing have been observed since that time. ${ }^{55} \mathrm{We}$ are unable to describe or account for any changes that may have occurred since 2015. Of note, VA opioid safety initiatives have not focused on women, and gender-specific changes in prescribing patterns since their implementation have not been examined.

Despite these limitations, this study has multiple strengths. To our knowledge, this is the first study to examine menopausal symptoms in relation to long-term opioids in midlife women, a population with increasing rates of opioid use $\mathrm{e}^{1}$ and opioid-related overdose mortality. ${ }^{8,9}$ We examined a large, diverse, nationally representative sample of midlife women Veterans who utilize VA care, and accounted for a wide range of demographic and clinical factors to assess for independent relationships and limit confounding. We characterized varied long-term opioid prescription patterns among patients with chronic pain, defined by electronic medical record and pharmacy data to enhance diagnostic validity. Despite inherent limitations, the use of this real-world data allows for examination of menopausal symptoms and chronic pain treatment as documented and managed within a large, integrated health care system. These findings identify a novel indicator for potentially problematic opioid prescription patterns within a high-risk period in the lifespan, which may help to inform interventions to improve comprehensive care for women with chronic pain.

\section{CONCLUSIONS}

Among midlife women Veterans with chronic pain, those with evidence of menopausal symptoms had increased odds of long-term opioids, high-dose long-term opioids, and longterm opioids co-prescribed with CNS depressants, independent of known demographic and clinical risk factors. Although rates of opioid use $\mathrm{e}^{1}$ and opioid-related mortality ${ }^{8}$ have risen dramatically among midlife women over the past two decades, drivers of increased risk in this vulnerable population had not been previously identified. These findings raise the possibility that menopausal symptoms are an underrecognized indicator of risk among midlife women with chronic pain, influencing treatment decisions that enhance risk for opioid-related disability and mortality. Safe and effective comprehensive care for midlife women with chronic pain should include recognition of the potential role of menopause in pain experience and management, and the possibility that pharmacological treatments for menopausal symptoms may inadvertently put women with chronic pain treated with longterm opioids at increased risk for opioid misuse and overdose.

Contributors: CJG and KHS were responsible for the study concept and design. KHS obtained funding and supervised the study. YL conducted the statistical analysis. All authors were involved in the interpretation of data. CJG drafted the manuscript, and all authors critically revised it for important intellectual content and approved the final version. The corresponding author attests that all listed authors meet authorship criteria and that no others meeting the criteria have been omitted. CJG is the guarantor and accepts overall responsibility for the accuracy of the data, its analysis, and this report.

Data Sharing: No additional data are available owing to a data use agreement with the Department of Veterans Affairs.

Corresponding Author: Carolyn J. Gibson, $\mathrm{PhD}, \mathrm{MPH}$; University of California, San Francisco, San Francisco, USA (e-mail: Carolyn. Gibson2@va.gov).

Funders This research was supported, in part, by the U.S. Department of Veterans Affairs Quality Enhancement Research Initiative (VA BUERI), "Evaluation of the Implementation of the Integrated Pain Team Clinic" (KHS, YL); CJG was supported by the VA Advanced Fellowship Program in Women's Health at the San Francisco VA Health Care System and VA Health Services Research \& Delivery CDA IK2 HXOO24O2 during the conduct of this study.

\section{Compliance with Ethical Standards:}

The study was approved by the institutional review boards of the University of California, San Francisco, and the Research and Development Committee of the San Francisco VA Health Care System.

Conflict of Interest: AH has received research grants from Pfizer Inc. and Astellas through the University of California, San Francisco to conduct research unrelated to this manuscript. All remaining authors declare that they do not have a conflict of interest.

Disclaimer: The funding organizations had no role in the design and conduct of the study; collection, management, analysis, and interpretation of the data; preparation or approval of the manuscript; or the decision to submit the manuscript for publication. The views expressed herein are those of the authors and do not necessarily represent the views of the US Department of Veterans Affairs or the University of California, San Francisco.

\section{REFERENCES}

1. Campbell CI, Weisner $\mathbf{C}$, Leresche $\mathbf{L}$, et al. Age and gender trends in long-term opioid analgesic use for noncancer pain. Am J Public Health. 2010;100(12):2541-2547. 
2. Bohnert AS, Ilgen MA, Trafton JA, et al. Trends and regional variation in opioid overdose mortality among Veterans Health Administration patients, fiscal year 2001 to 2009. The Clinical journal of pain. 2014;30(7):605-612.

3. Higgins DM, Kerns RD, Brandt CA, et al. Persistent pain and comorbidity among Operation Enduring Freedom/Operation Iraqi Freedom/operation New Dawn veterans. Pain Med. 2014;15(5):782790.

4. Fillingim RB, King CD, Ribeiro-Dasilva MC, Rahim-Williams B, Riley JL, 3rd. Sex, gender, and pain: a review of recent clinical and experimental findings. J Pain. 2009; 10(5):447-485.

5. Kroll-Desrosiers AR, Skanderson M, Bastian LA, et al. Receipt of prescription opioids in a national sample of pregnant veterans receiving Veterans Health Administration care. Women's Health Issues. 2016;26(2):240-246.

6. Mosher H, Krebs E, Carrel M, Kaboli P, Vander Weg M, Lund B. Trends in prevalent and incident opioid receipt: an observational study in veterans health administration 2004-2012. Journal of general internal medicine. 2015;30(5):597-604.

7. Darnall BD, Stacey BR. Sex differences in long-term opioid use: cautionary notes for prescribing in women. Arch Intern Med. 2012;172(5):431-432.

8. CDC. Prescription Painkiller Overdoses: A Growing Epidemic, Especially Among Women. https://www.cdc.gov/vitalsigns/ prescriptionpainkilleroverdoses/index.html. Published 2017. Accessed June 21, 2019.

9. Calcaterra S, Glanz J, Binswanger IA. National trends in pharmaceutical opioid related overdose deaths compared to other substance related overdose deaths: 1999-2009. Drug Alcohol Depend. 2013;131(3):263270.

10. Magliano M. Menopausal arthralgia: Fact or fiction. Maturitas. 2010;67(1):29-33.

11. Craft RM. Modulation of pain by estrogens. Pain. 2007;132 Suppl 1:S312 .

12. Meriggiola MC, Nanni M, Bachiocco V, Vodo S, Aloisi AM. Menopause affects pain depending on pain type and characteristics. Menopause. 2012;19(5):517-523.

13. Attarian H, Hachul H, Guttuso T, Phillips B. Treatment of chronic insomnia disorder in menopause: evaluation of literature. Menopause. 2015;22(6):674-684.

14. Berlin RK, Butler PM, Perloff MD. Gabapentin Therapy in Psychiatric Disorders: A Systematic Review. Prim Care Companion CNS Disord. 2015; 17(5).

15. Nonhormonal management of menopause-associated vasomotor symptoms: 2015 position statement of The North American Menopause Society. Menopause. 2015;22(11):1155-1172; quiz 1173-1154.

16. Masnoon N, Shakib S, Kalisch-Ellett L, Caughey GE. What is polypharmacy? A systematic review of definitions. BMC Geriatr. 2017;17(1):230

17. Frayne SM, Phibbs, C.S., Saecho, F., Maisel, N.C., Friedman, S.A. Finlay, A., Berg, E., Balasubramanian, V., Dally, S.K., Ananth, L., Romodan, Y., Lee, J., Iqbal, S., Hayes, P.M., Zephyrin, L., Whitehead, A. Torgal, A., Katon, J.G., Haskell, S. . Soucebook: Women Veterans in the Veterans Health Administration. Vol Volume 3. Sociodemographics, Utilization, Costs of Care, and Health Profile. Washington, D.C.: Women's Health Evaluation Initiative, Women's Health Services, Veterans Health Administration, Department of Veterans Affairs.; February 2014

18. Gold EB, Colvin A, Avis N, et al. Longitudinal analysis of the association between vasomotor symptoms and race/ethnicity across the menopausal transition: study of women's health across the nation. Am J Public Health 2006;96(7): 1226-1235.

19. Seal KH, Bertenthal D, Barnes DE, et al. Association of Traumatic Brain Injury With Chronic Pain in Iraq and Afghanistan Veterans: Effect of Comorbid Mental Health Conditions. Arch Phys Med Rehabil. 2017;98(8): 1636-1645.

20. Oliva EM, Midboe AM, Lewis ET, et al. Sex differences in chronic pain management practices for patients receiving opioids from the Veterans Health Administration. Pain Med. 2015;16(1):112-118.

21. VA/DoD Opioid Therapy for Chronic Pain Work Group. VA/DoD Clinical Practice Guideline for Opioid Therapy for Chronic Pain, Vol. 3. https:// www.healthquality.va.gov/guidelines/Pain/cot/VADoDOTCPG022717. pdf Published 2017. Accessed June 21, 2019.

22. Jones CM, Mack KA, Paulozzi LJ. Pharmaceutical overdose deaths, United States, 2010. JAMA. 2013;309(7):657-659.

23. Smith RV, Havens JR, Walsh SL. Gabapentin misuse, abuse and diversion: a systematic review. Addiction. 2016;111(7):1160-1174.
24. Evoy KE, Morrison MD, Saklad SR. Abuse and Misuse of Pregabalin and Gabapentin. Drugs. 2017;77(4):403-426.

25. Gomes T, Juurlink DN, Antoniou T, Mamdani MM, Paterson JM, van den Brink W. Gabapentin, opioids, and the risk of opioid-related death: A population-based nested case-control study. PLoS Med. 2017;14(10):e1002396.

26. Abrahamsson T, Berge J, Ojehagen A, Hakansson A. Benzodiazepine, $\mathrm{z}$-drug and pregabalin prescriptions and mortality among patients in opioid maintenance treatment-A nation-wide register-based open cohort study. Drug Alcohol Depend. 2017;174:58-64.

27. Slavova S, Miller A, Bunn TL, et al. Prevalence of gabapentin in drug overdose postmortem toxicology testing results. Drug Alcohol Depend. 2018; 186:80-85.

28. Burgess DJ, Nelson DB, Gravely AA, et al. Racial differences in prescription of opioid analgesics for chronic noncancer pain in a national sample of veterans. J Pain. 2014;15(4):447-455.

29. Seal KH, Shi Y, Cohen G, et al. Association of mental health disorders with prescription opioids and high-risk opioid use in US veterans of Iraq and Afghanistan. JAMA. 2012;307(9):940-947.

30. Pamuk ON, Cakir N. The variation in chronic widespread pain and other symptoms in fibromyalgia patients. The effects of menses and menopause. Clin Exp Rheumatol. 2005;23(6):778-782.

31. Martinez-Jauand $\mathbf{M}$, Sitges C, Femenia J, et al. Age-of-onset of menopause is associated with enhanced painful and non-painful sensitivity in fibromyalgia. Clin Rheumatol. 2013;32(7):975-981.

32. Paller CJ, Campbell CM, Edwards RR, Dobs AS. Sex-based differences in pain perception and treatment. Pain Med. 2009;10(2):289-299.

33. Thurston RC, Bromberger JT, Joffe $\mathbf{H}$, et al. Beyond frequency: who is most bothered by vasomotor symptoms? Menopause. 2008;15(5):841847.

34. Maki PM, Freeman EW, Greendale GA, et al. Summary of the National Institute on Aging-sponsored conference on depressive symptoms and cognitive complaints in the menopausal transition. Menopause. 2010;17(4):815-822.

35. Huang AJ, Moore EE, Boyko EJ, et al. Vaginal symptoms in postmenopausal women: self-reported severity, natural history, and risk factors. Menopause. 2010;17(1):121-126.

36. Elavsky S, Gonzales JU, Proctor DN, Williams N, Henderson Vw. Effects of physical activity on vasomotor symptoms: examination using objective and subjective measures. Menopause. 2012;19(10):1095-1103.

37. Finan PH, Goodin BR, Smith MT. The association of sleep and pain: an update and a path forward. J Pain. 2013;14(12):1539-1552.

38. Patel KV, Cochrane BB, Turk DC, et al. Association of Pain With Physical Function, Depressive Symptoms, Fatigue, and Sleep Quality Among Veteran and non-Veteran Postmenopausal Women. Gerontologist. 2016;56 Suppl 1:S91-101.

39. Sullivan MD, Edlund MJ, Zhang L, Unutzer J, Wells KB. Association between mental health disorders, problem drug use, and regular prescription opioid use. Arch Intern Med. 2006;166(19):2087-2093.

40. Gorka SM, Fitzgerald DA, de Wit H, Angstadt M, Phan KL. Opioid modulation of resting-state anterior cingulate cortex functional connectivity. J Psychopharmacol. 2014;28(12):1115-1124.

41. Beebe FA, Barkin RL, Barkin S. A clinical and pharmacologic review of skeletal muscle relaxants for musculoskeletal conditions. Am $J$ Ther. 2005; 12(2): 151-171

42. Olfson M, King M, Schoenbaum M. Benzodiazepine use in the United States. JAMA Psychiatry. 2015;72(2):136-142.

43. Cooper TE, Derry S, Wiffen PJ, Moore RA. Gabapentin for fibromyalgia pain in adults. Cochrane Database Syst Rev. 2017;1:CD012188.

44. Guttuso T, Jr. Effective and clinically meaningful non-hormonal hot flash therapies. Maturitas. 2012;72(1):6-12.

45. Peckham AM, Fairman KA, Sclar DA. All-Cause and Drug-Related Medical Events Associated with Overuse of Gabapentin and/or Opioid Medications: A Retrospective Cohort Analysis of a Commercially Insured US Population. Drug Saf. 2018;41(2):213-228.

46. Jann M, Kennedy WK, Lopez G. Benzodiazepines: a major component in unintentional prescription drug overdoses with opioid analgesics. $J$ Pharm Pract. 2014;27(1):5-16.

47. Campbell G, Nielsen S, Larance B, et al. Pharmaceutical Opioid Use and Dependence among People Living with Chronic Pain: Associations Observed within the Pain and Opioids in Treatment (POINT) Cohort. Pain Med. 2015;16(9): 1745-1758.

48. Edlund MJ, Martin BC, Fan MY, Devries A, Braden JB, Sullivan MD. Risks for opioid abuse and dependence among recipients of chronic opioid therapy: results from the TROUP study. Drug Alcohol Depend. 2010;112(1-2):90-98. 
49. Jones CM, McAninch JK. Emergency Department Visits and Overdose Deaths From Combined Use of Opioids and Benzodiazepines. Am J Prev Med. 2015;49(4):493-501.

50. Darnall BD, Stacey BR, Chou R. Medical and psychological risks and consequences of long-term opioid therapy in women. Pain Med. 2012;13(9):1181-1211.

51. Guina J, Rossetter SR, De RB, Nahhas RW, Welton RS. Benzodiazepines for PTSD: A Systematic Review and Meta-Analysis. $J$ Psychiatr Pract. 2015;21(4):281-303.

52. Nielsen $\mathbf{S}$, Lintzeris $\mathbf{N}$, Bruno $\mathbf{R}$, et al. Benzodiazepine use among chronic pain patients prescribed opioids: associations with pain, physical and mental health, and health service utilization. Pain Med. 2015;16(2):356-366.

53. Dominick KL, Bosworth HB, Dudley TK, Waters SJ, Campbell LC Keefe FJ. Patterns of opioid analgesic prescription among patients with osteoarthritis. J Pain Palliat Care Pharmacother. 2004;18(1):31-46.
54. Meghani SH, Byun E, Gallagher RM. Time to take stock: a meta-analysis and systematic review of analgesic treatment disparities for pain in the United States. Pain Med. 2012;13(2):150-174.

55. Hadlandsmyth $\mathbf{K}$, Mosher $\mathbf{H}$, Vander Weg MW, Lund BC. Decline in Prescription Opioids Attributable to Decreases in Long-Term Use: A Retrospective Study in the Veterans Health Administration 2010-2016. $J$ Gen Intern Med. 2018;33(6):818-824.

Publisher's Note Springer Nature remains neutral with regard to jurisdictional claims in published maps and institutional affiliations. 